\title{
High-frequency power of heart rate variability can predict the outcome of thoracic surgical patients with acute respiratory distress syndrome on admission to the intensive care unit: a prospective, single-centric, case-controlled study
}

I-Chen Chen ${ }^{1}$, Chew-Teng Kor ${ }^{2}$, Ching-Hsiung Lin³,4, Jane Kuo ${ }^{5}$, Jang-Zern Tsai' ${ }^{6}$, Wen-Je Ko ${ }^{1}$ and Cheng-Deng $\mathrm{KuO}^{3,7^{*}}$ (D)

\begin{abstract}
Background: The morbidity and mortality of acute respiratory distress syndrome (ARDS) remains high, and the strategic focus of ARDS research has shifted toward identifying patients at high risk of mortality early in the course of illness. This study intended to identify the heart rate variability (HRV) measure that can predict the outcome of patients with ARDS on admission to the surgical intensive care unit (SICU).

Methods: Patients who had lung or esophageal cancer surgery were included either in the ARDS group $(n=21)$ if they developed ARDS after surgery or in the control group $(n=11)$ if they did not. The ARDS patients were further stratified into survivors and non-survivors subgroups according to their outcomes. HRV measures of the patients were used for statistical analysis.

Results: The mean RR interval (mRRI), high-frequency power (HFP) and product of low-/high-frequency power ratio tidal volume and tidal volume $\left(L H R^{*} V_{T}\right)$ were significantly lower $(p<0.05)$, while the normalized HFP to $\bigvee_{T}$ ratio $\left(n H F P N_{T}\right)$ was significantly higher in the ARDS patients $(p=0.011)$. The total power (TP), low-frequency power (LFP), HFP and HFPN $N_{T}$ were all significantly higher in the non-survived ARDS patients, whereas Richmond Agitation-Sedation Scale (RASS) was significantly lower in the non-survived ARDS patients. After adjustment for RASS, age and gender, firth logistic regression analysis identified the HFP, TP as the significant independent predictors of mortality for ARDS patients.

Conclusions: The vagal modulation of thoracic surgical patients with ARDS was enhanced as compared to that of nonARDS patients, and the non-survived ARDS patients had higher vagal activity than those of survived ARDS patients. The vagal modulation-related parameters such as TP and HFP were independent predictors of mortality in patients with ARDS on admission to the SICU, and the HFP was found to be the best predictor of mortality for those ARDS patients. Increased vagal modulation might be an indicator for poor prognosis in critically ill patients following thoracic surgery.
\end{abstract}

Keywords: Acute respiratory distress syndrome, Heart rate variability, Outcome, Mortality

\footnotetext{
*Correspondence: cdkuo23@gmail.com

${ }^{3}$ Division of Chest Medicine, Department of Internal Medicine, Changhua

Christian Hospital, Changhua, Taiwan

7Laboratory of Biophysics, Department of Medical Research, Taipei Veterans

General Hospital, Taipei, Taiwan

Full list of author information is available at the end of the article
} 


\section{Background}

Acute respiratory distress syndrome (ARDS) is a life threatening lung condition that affects both medical and surgical patients $[1,2]$. Postoperative ARDS is a recognized complication after lung resection or esophagectomy for cancer [3-5]. The incidence of ARDS after these procedures was $1-3 \%[3,6]$, and the overall hospital mortality rates associated with ARDS were over 40\% [5-8].

Many scoring systems have been developed and used in the intensive care unit (ICU) to monitor the treatment and predict the outcomes of patients with ARDS. For instance, Navarrete-Navarro et al. [9] showed that the ICU mortality of trauma patients with ARDS was related to the Acute Physiology and Chronic Health Evaluation (APACHE) III score and $\mathrm{PaO}_{2} / \mathrm{FIO}_{2}$ on the 3rd day. Luecke et al. [10] showed that the APACHE II was the only clinical predictor for mortality on admission to the ICU. Bauman et al. [11] showed that the lung injury score was reliable for predicting mortality in critically ill surgical patients.

The autonomic nervous system is important for the maintenance of homeostasis. A wide range of pathophysiologic conditions can influence the balance in the autonomic nervous system. Heart rate variability (HRV) refers to the variation of interbeat intervals due to respiration and other physiological inputs. The assessment of HRV is based on the analysis of consecutive normal $\mathrm{R}-\mathrm{R}$ intervals, and may provide clinicians with quantitative information about cardiac autonomic nervous modulation. HRV can be quantified by time domain and frequency domain parameters. Thus, HRV analysis has become a useful non-invasive technique for evaluation of cardiac autonomic nervous modulation in many kinds of illnesses [12].

Previous studies have reported that HRV measures are decreased in survivors of cardiac arrest [13]. Some studies found that the standard deviation of normal-tonormal QRS intervals (SDNN), one of six commonly used time-domain HRV measures, is a significant parameter for long-term prognosis in patients with acute myocardial infarction [14, 15]. Tibby et al. [16] showed that the loss of HRV occurs with increasing organ failure, and that this effect is better demonstrated by the power-law model of HRV than by other measures of HRV. Annane et al. [17] reported that the low-frequency (LF) component of the oscillations in heart rate and diastolic blood pressure variability are dramatically reduced in patients with septic shock, and that the decrease in the LF component may identify septic patients with a high level of sympathetic activation. Pontet et al. [18] demonstrated that reduction of HRV in patients on ICU admission may be useful in identifying septic patients at risk for the development of multiple organ dysfunction syndromes. In patients with severe sepsis, depressed sympathetic modulation has been found to be indicative of poor outcome [19]. In patients in the emergency department who have been successfully resuscitated after out-of-hospital cardiac arrest, the initial HRV measures resemble those of severe sepsis and are capable of predicting 24-h mortality [20, 21]. In the emergency department, the characteristics of HRV can predict impending septic shock in patients with sepsis [22]. These studies suggest that HRV measures might be useful for the monitoring of patients with various kinds of diseases, including ARDS, and for predicting their prognosis.

Despite significant advances in the management of patients with ARDS in the past fifty years, the morbidity and mortality of ARDS remains high, and the strategic focus of ARDS research has shifted toward identifying patients with or at high risk of ARDS early in the course of their illnesses [23]. Thus, the aim of this study was to evaluate the possibility of using HRV measures to predict the outcome in patients with ARDS on admission to the surgical intensive unit (SICU).

\section{Methods \\ Research Design}

This was a prospective, single-centric, case-controlled study. The study protocol has been approved by the Institutional Review Boards of National Taiwan University Hospital (NTUH200808065R) and Taipei Veterans General Hospital (VGHIRB97-01-02A), and written informed consent was obtained from the patients or the next of kin of the patients before their enrollment in the study.

\section{Study Participants}

This study was conducted in the SICU of National Taiwan University Hospital. All the recruited patients were over 18 years old. They were partitioned into an ARDS group and a control group. The ARDS group consisted of patients who had received thoracic surgery because of lung or esophageal cancer and were transferred to the SICU for intensive care because of ARDS later. The control group consisted of patients who had received thoracic surgery because of lung or esophageal cancer and were transferred to the SICU for postoperative care. The ARDS was diagnosed according to the Berlin Definition [2]. A draft definition proposed 3 mutually exclusive categories of ARDS based on the degree of hypoxemia: mild $\left(200 \mathrm{mmHg}<\mathrm{PaO}_{2} / \mathrm{FIO}_{2} \leq\right.$ $300 \mathrm{mmHg})$, moderate $\left(100 \mathrm{mmHg}<\mathrm{PaO}_{2} / \mathrm{FIO}_{2} \leq\right.$ $200 \mathrm{mmHg})$, and severe $\left(\mathrm{PaO}_{2} / \mathrm{FIO}_{2} \leq 100 \mathrm{mmHg}\right)$ with 4 ancillary variables for severe ARDS: radiographic severity, respiratory system compliance $(\leq 40 \mathrm{~mL} / \mathrm{cm}$ $\left.\mathrm{H}_{2} \mathrm{O}\right)$, positive end-expiratory pressure $\left(\geq 10 \mathrm{~cm} \mathrm{H}_{2} \mathrm{O}\right)$, and corrected expired volume per minute $(\geq 10 \mathrm{~L} / \mathrm{min})$. Patients with severe coronary artery disease, persistent 
arrhythmia, cardiac pacing, diabetes mellitus, cerebral vascular accident, or major diseases of kidney or autoimmune system were excluded from the study.

\section{Physiological Measurements}

All patients required intubation and mechanical ventilation. The acute lung injury score (ALIS) [24], alveolar-arterial oxygen difference $\left(\mathrm{AaDO}_{2}\right)$, APACHE II [25], demographic data, vital signs, medications, ventilator parameters including respiratory rate $(\mathrm{RR})$, inspiratory pressure $\left(\mathrm{P}_{\text {insp }}\right)$, inspiration time $\left(\mathrm{T}_{\text {insp }}\right)$, tidal volume $\left(\mathrm{V}_{\mathrm{T}}\right)$, positive end-expiratory pressure (PEEP), minute ventilation (MV), fraction of inspired oxygen $\left(\mathrm{FIO}_{2}\right)$, dynamic compliance (Cdyn), and arterial blood gases data were recorded within $4 \mathrm{~h}$ of admission to the SICU. Electrocardiographic (ECG) signals were recorded for $12 \mathrm{~min}$ in supine position using the MP35 multichannel recorder (BIOPAC Systems, Goleta, CA, USA). The primary outcome measure was survival at discharge from the SICU. Patients who survived the ARDS were classified as the survivors, while those patients who did not survive the ARDS were classified as non-survivors. Clinical information obtained in the SICU and the outcomes of the patients were blinded to the investigator who performed the HRV analysis and clinical data collection.

\section{HRV Analysis}

Power spectral density (PSD) analysis by using parametric autoregressive modeling or non-parametric Fourier transform provides the basic information about the power (variance) distributes of experimental data as a function of frequency. The Fourier transform decomposes a signal into its constituent frequencies. The Fourier transform of a signal is a complex-valued function of frequency, whose absolute value represents the amount of that particular frequency present in the signal. The power of a particular frequency band is calculated by integrating the PSD within that frequency band. Thus, the Fourier transform is the frequency domain representation of the original signal [26].

The method used for the HRV analysis adhered to the standards laid down by the Task Force of the European Society of Cardiology and the North American Society of Pacing and Electrophysiology [12]. All ectopic beats were removed and the missing data were replaced by interpolated beats derived from the nearest valid data. Any patient with more than $5 \%$ of ectopic beats was excluded from the study. The last 512 stationary RR intervals (RRI) were used for HRV analysis.

The time domain HRV measures included mRRI, standard deviation of RRI $\left(\mathrm{SD}_{\mathrm{RR}}\right)$, coefficient of variation of RRI $\left(\mathrm{CV}_{\mathrm{RR}}\right)$, and root mean squared successive difference of RRI (RMSSD). The power spectrum of RRI was obtained by means of fast Fourier transformation (Mathcad 15, Mathsoft Inc.). The areas under the spectral peaks within the range of $0.01-0.04 \mathrm{~Hz}, 0.04-0.15 \mathrm{~Hz}, 0$. $15-0.5 \mathrm{~Hz}$, and $0.01-0.5 \mathrm{~Hz}$ were defined as the very low-frequency power (VLFP), LFP, high frequency power (HFP), and TP, respectively. The normalized VLFP $(\mathrm{nVLFP}=\mathrm{VLFP} / \mathrm{TP} \times 100)$ was used as the index of renin-angiotensin-aldosterone modulation, thermal regulation and vagal withdrawal; the normalized LFP $(\mathrm{nLFP}=\mathrm{LFP} / \mathrm{TP} \times 100)$ as the index of combined sympathetic and vagal activities; the normalized HFP (nHFP = HFP/TP $\times 100$ ) and HFP as the index of cardiac vagal activity; and the low-/high-frequency power ratio (LHR $=\mathrm{LFP} / \mathrm{HFP}$ ) as the index of sympathovagal balance. Since the HFP and nHFP can be influenced by carbon dioxide, respiratory rate and tidal volume $\left(\mathrm{V}_{\mathrm{T}}\right)$ [27], the $\mathrm{HFP} / \mathrm{V}_{\mathrm{T}}$ and $\mathrm{nHFP} / \mathrm{V}_{\mathrm{T}}$ were used as the $\mathrm{V}_{\mathrm{T}}$-corrected indices of vagal modulation, and the $L H R^{*} V_{T}$ was used as the $\mathrm{V}_{\mathrm{T}}$-corrected index of sympathovagal balance [20].

\section{Statistical Analysis}

Continuous variables were compared between the two groups of patients using Mann-Whitney U test. Fisher's exact test was used for comparisons of categorical data. Pearson product moment analysis was performed to find the correlations among HRV measures and clinical variables of the patients. The Firth logistic regression and multiple linear regression models were employed to identify the most important independent predictors of mortality and ICU stay day, respectively. Firth's penalized likelihood approach was used to reduce the bias of the parameter estimates due to small sample size. Significant HRV measures in the univariate analyses of differences between the two subgroups of ARDS patients were included in the multivariate analyses. In this study, the 10 events per variable (EPV - 10) rule [28, 29] was used in logistic regression model to avoid the overfitting problem, which is a generally accepted criterion in multivariable analysis. With a sample size of 32 patients (11 patients in the control group and 21 patients in the ARDS group), the inclusion of only three variables in the multivariate analysis to ensure adequate statistical power is reasonable. The binary receiver operating characteristic (ROC) curves for statistically independent variables associated with mortality were drawn. All statistical analyses were performed using $\mathrm{R}$ software (version i386 3.3.2, https://www.r-project.org/) and the contributed R package logistic for Firth's penalized-likelihood logistic regression. A $p<0.05$ was considered statistically significant.

\section{Results}

During the 2 years study period, 22 patients developed ARDS among the 817 patients that received lung or esophageal surgery. Thus the incidence rate of ARDS after thoracic surgery for lung or esophageal surgery was $2.69 \%$. Among those 22 ARDS patients, 15 were included in the 
ARDS group while 7 were not because of arrhythmia. Six patients who were not operated during this admission but had thoracic surgery within past 1 year and developed ARDS due to rapidly progressing pneumonia were also admitted and included in the ARDS group. Thus, there were 11 patients in the non-ARDS group and 21 patients in the ARDS group.

Fentanyl $\left(5 \sim 10 \mu \mathrm{g} \cdot \mathrm{hr}^{-1}\right)$ was administered to the patients during the post-operative period for postsurgical pain killing. The Fentanyl was given to the nonARDS patients for $24-48 \mathrm{~h}$, while it was given to the ARDS patients for more than $48 \mathrm{~h}$. Midazolam (1 $2 \mathrm{mg} / \mathrm{h}$ ) was used to maintain Richmond AgitationSedation Scale (RASS) $0 \sim-2$ in both groups, and dopamine and norepinephrine $\left(0.05 \sim 0.11 \mu \mathrm{g} \cdot \mathrm{hr}^{-1} \cdot \mathrm{min}^{-1}\right)$ were used in 8 patients in the ARDS group to keep mean blood pressure $>60 \mathrm{mmHg}$ to maintain proper cerebral perfusion pressure. The ECG recordings were taken within $4 \mathrm{~h}$ of transfer to the SICU in all patients.

In the control group, 6 patients had lung cancer and 5 patients had esophageal cancer. In the ARDS group, 9 patients had lung cancer, 5 patients had esophageal cancer, 1 patient had esophageal rupture, and 6 patients had pneumonia-induced ARDS after the thoracic surgery. Six patients out of 11 patients in the control group were classified as American Society of Anesthesiologists (ASA) I, and 5 patients as ASA II. For the 21 patients in the ARDS group, 1 patient was classified as ASA I, 5 patients as ASA II, 4 patients as ASA III. Six patients in the ARDS group had no ASA classification because they were not operated during this admission, but had thoracic surgery within past 1 year, and were admitted due to ARDS caused by rapidly progressing pneumonia (Table 1 ).

Ten patients in the control group received videoassisted thoracic surgery (VATS) for lobectomy or esophageal resection, and 1 patient received VATS for laminectomy because of lung cancer metastasis. In the ARDS group, 12 patients received VATS for lobectomy or esophageal resection, 3 patients received open lung surgery, and 6 patients received thoracic surgery within the past 1 year who were admitted to the SICU because of ARDS caused by pneumonia (Table 1 ).

In the control group, 2 patients received bronchus blocker, and 9 patients received double-lumen intubation. In the ARDS group, 15 patients received thoracic surgery during this admission; among them, 5 patients received bronchus blocker and 10 patients received double-lumen intubation. All the 26 patients who received thoracic surgery during this admission were operated under Desflurane and Sevoflurane anesthesia (minimum alveolar concentration: 0.8-1.1 Vol\%). Five out of the 11 patients in the control group received blood transfusion; the transfusion rate in the control group was $45.5 \%$. In the ARDS group, 6 out of the 15 patients who received thoracic surgery during this admission had blood transfusion. Therefore, the transfusion rate was $40 \%$ in the ARDS group. The duration of surgery in the control group was $255(245-450)$ minutes (median and interquartile range), whereas the duration of surgery in the ARDS group was 250 (165-375) minutes (Table 1).

Tables 1 shows that the ARDS patients had higher RR, required higher $\mathrm{FIO}_{2}$ and PEEP during ventilation. The $\mathrm{V}_{\mathrm{T}}, \mathrm{Cdyn}, \mathrm{PaO}_{2}$ and $\mathrm{PaO}_{2} / \mathrm{FIO}_{2}$, intraoperative intake/output (I/O) of the ARDS patients was significantly lower $(p$ $<0.01$ ), whereas the arterial partial pressure of carbon dioxide $\left(\mathrm{PaCO}_{2}\right)$, bicarbonate $\left(\mathrm{HCO}_{3}{ }^{-}\right)$, ASA classification, and $\mathrm{AaDO}_{2}$ of the ARDS patients were significantly higher than those of non-ARDS patients $(p<0.05)$. The mRRI, HFP and LHR* $V_{\mathrm{T}}$ were significantly lower $(p<0$. $05)$, while the $n H F P / V_{T}$ was significantly higher in the ARDS patients $(p=0.011)$. Table 2 shows that there were no significant differences in most ventilator settings, disease severity scores including ALIS, $\mathrm{AaDO}_{2}$, APACHE II, intraoperative anesthesia control, blood transfusion rate, fluid balance, and blood gas data between the survivors and non-survivors of ARDS. However, the $\mathrm{P}_{\text {insp }}, \mathrm{PaCO}_{2}$, $\mathrm{HCO}_{3}{ }^{-}$, TP, LFP, HFP, and HFP/V $\mathrm{V}_{\mathrm{T}}$ of the non-survivors were higher than those of the survivors $(p<0.05)$, and RASS of the non-survivors was significantly lower than that of the survivors $(p=0.040)$.

Pearson product moment analysis among the significantly different HRV measures between the survived and non-survived ARDS patients showed that the TP, LFP, $\mathrm{HFP}$, and HFP/ $\mathrm{V}_{\mathrm{T}}$ also correlated significantly and positively with one another (Table 3), but these HRV measures did not correlate with RASS.

Firth logistic regression analysis was used to assess the risk of mortality (dependent variable) in ARDS patients. The ASA classification, intraoperative anesthesia, fluid balance, drugs, etc., were not significantly different between the survivors and non- survivors of ARDS; only the RASS of the non-survivors was significantly lower than that of the survivors (Table 2). In univariate analysis, the TP, HFP and RASS were found to be the significant predictors of mortality for ARDS patients in the SICU $(p<0.05)$ (Table 4). Since the TP and HFP were highly correlated with each other while the RASS did not correlate with either TP or HFP (Table 3), two separate models in multivariate analysis including HFP and TP adjusted for RASS, age and gender were used. After adjustment for RASS, age and gender, the HFP $(p=0$. $025)$ and TP $(p=0.024)$ were found to be the significant independent predictors of mortality in ARDS patients in the SICU (Table 4).

As depicted in Fig. 1, the AUCs and 95\% confidence intervals (CI) of TP and HFP in predicting mortality in ARDS patients on admission to the SICU were 0.850 
Table 1 Comparison between patients with and without ARDS

\begin{tabular}{|c|c|c|c|}
\hline \multirow{3}{*}{ Clinical data } & \multirow{2}{*}{$\begin{array}{l}\text { Non-ARDS } \\
(n=11)\end{array}$} & \multirow{2}{*}{$\begin{array}{l}\text { ARDS } \\
(n=21)\end{array}$} & \multirow[t]{2}{*}{$p$ value } \\
\hline & & & \\
\hline & & & \\
\hline & $62(57-67)$ & $63(50-71)$ & 0.889 \\
\hline Body height $(\mathrm{cm})$ & $154(151-171)$ & $167(163-170)$ & 0.176 \\
\hline Body weight (kg) & $65(57-76)$ & $63(58-72)$ & 0.953 \\
\hline APACHE ॥ & $9(6-12)$ & $16(11-19)$ & 0.002 \\
\hline \multicolumn{4}{|l|}{ Pre-operation } \\
\hline Lung cancer/Esophageal cancer & $6 / 5$ & $9 / 5$ & 0.697 \\
\hline Hypertension (Yes/No) & $3 / 8$ & $4 / 17$ & 0.667 \\
\hline ASA & $1(1-2)$ & $2(2-3)$ & 0.005 \\
\hline VATS/open surgery & $11 / 0$ & $12 / 3$ & 0.667 \\
\hline Blood transfusion (Yes/No) & $5 / 6$ & $5 / 10$ & 0.457 \\
\hline Airway management & $9 / 2$ & $10 / 5$ & 0.540 \\
\hline \multicolumn{4}{|l|}{ (double-lumen tube/bronchus blocker) } \\
\hline Anesthesia (volatile/intravenous) & $11 / 0$ & $15 / 0$ & 1.000 \\
\hline Surgery time (minute) & $255(245-450)$ & $250(165-375)$ & 0.474 \\
\hline Intraoperative I/O (ml) & $2000(1500-2400)$ & $1300(650-1800)$ & 0.015 \\
\hline ICU stay days (day) & $4(2-4)$ & $25(13-42)$ & $<0.001$ \\
\hline RASS & $0(0-0)$ & $-1(-1-0)$ & 0.001 \\
\hline Ventilator free hours & $0(0-0)$ & $48(24-68)$ & NA \\
\hline \multicolumn{4}{|l|}{ Medications } \\
\hline Midazolam (Yes/No) & $4 / 7$ & $20 / 1$ & $<0.001$ \\
\hline Fentanyl (Yes/No) & $11 / 0$ & $21 / 0$ & 1.000 \\
\hline Norepinephrine (Yes/No) & $0 / 11$ & $8 / 13$ & 0.021 \\
\hline Dopamine (Yes/No) & $0 / 11$ & $3 / 17$ & 0.531 \\
\hline \multicolumn{4}{|l|}{ Ventilator settings } \\
\hline $\mathrm{FlO}_{2}$ & $0.40(0.40-0.40)$ & $0.70(0.60-0.93)$ & $<0.001$ \\
\hline PEEP $\left(\mathrm{cmH}_{2} \mathrm{O}\right)$ & $5.0(5.0-7.6)$ & $10.0(9.7-12.0)$ & $<0.001$ \\
\hline $\mathrm{RR}(\mathrm{bpm})$ & $12(12-13)$ & $17(16-27)$ & $<0.001$ \\
\hline$P_{\text {insp }}\left(\mathrm{cmH}_{2} \mathrm{O}\right)$ & $20(20-20)$ & $20(17-22)$ & 1.000 \\
\hline $\mathrm{T}_{\text {insp }}(\mathrm{sec})$ & $0.9(0.9-1.0)$ & $0.9(0.8-1.0)$ & 0.546 \\
\hline $\mathrm{V}_{\mathrm{T}}(\mathrm{ml})$ & $490(470-617)$ & $420(380-540)$ & 0.004 \\
\hline MV (I/min) & $6.0(5.6-8.3)$ & $9.0(6.6-10.6)$ & 0.142 \\
\hline Cdyn $\left(\mathrm{ml} / \mathrm{cmH}_{2} \mathrm{O}\right)$ & $25.0(23.5-32.0)$ & $21.1(18.0-26.7)$ & 0.010 \\
\hline \multicolumn{4}{|l|}{ Arterial gas analysis } \\
\hline $\mathrm{pH}$ & $7.42(7.37-7.46)$ & $7.44(7.39-7.47)$ & 0.524 \\
\hline $\mathrm{PaO}_{2}(\mathrm{mmHg})$ & $171(133-230)$ & 79 (67-97) & $<0.001$ \\
\hline $\mathrm{PaCO}_{2}(\mathrm{mmHg})$ & $32(27-39)$ & $39(32-42)$ & 0.043 \\
\hline $\mathrm{HCO}_{3}^{-}(\mathrm{mmol} / \mathrm{l})$ & $20(19-22)$ & $26(21-28)$ & 0.017 \\
\hline $\mathrm{PaO}_{2} / \mathrm{FlO}_{2}(\mathrm{mmHg})$ & $477(343-559)$ & $106(86-171)$ & $<0.001$ \\
\hline $\mathrm{AaDO}_{2}(\mathrm{mmHg})$ & $47(34-104)$ & $368(266-531)$ & $<0.001$ \\
\hline \multicolumn{4}{|l|}{ Time domain HRV measures } \\
\hline mRRI (ms) & $684(589-874)$ & $604(524-649)$ & 0.017 \\
\hline $\mathrm{SD}_{\mathrm{RR}}(\mathrm{ms})$ & $32(28-43)$ & $29(25-36)$ & 0.132 \\
\hline
\end{tabular}


Table 1 Comparison between patients with and without ARDS (Continued)

\begin{tabular}{|c|c|c|c|}
\hline & \multirow{2}{*}{$\begin{array}{l}\text { Non-ARDS } \\
(n=11)\end{array}$} & \multirow{2}{*}{$\begin{array}{l}\text { ARDS } \\
(n=21)\end{array}$} & \multirow[t]{2}{*}{$p$ value } \\
\hline & & & \\
\hline$C V_{R R}(\%)$ & $4.7(4.5-4.9)$ & $4.5(4.5-5.0)$ & 0.284 \\
\hline RMSSD (ms) & $31(28-41)$ & $29(25-37)$ & 0.204 \\
\hline \multicolumn{4}{|c|}{ Frequency domain HRV measures } \\
\hline $\mathrm{TP}\left(m s^{2}\right)$ & $267(206-614)$ & $212(134-316)$ & 0.068 \\
\hline $\operatorname{VLFP}\left(m s^{2}\right)$ & $29(22-92)$ & $21(11-47)$ & 0.068 \\
\hline $\operatorname{LFP}\left(\mathrm{ms}^{2}\right)$ & $73(48-168)$ & $54(39-78)$ & 0.052 \\
\hline $\operatorname{HFP}\left(\mathrm{ms}^{2}\right)$ & $171(131-387)$ & $122(83-176)$ & 0.043 \\
\hline $\mathrm{HFP} N_{\mathrm{T}}\left(\mathrm{ms}^{2} / \mathrm{ml}\right)$ & $0.35(0.22-0.81)$ & $0.31(0.21-0.44)$ & 0.383 \\
\hline nVLFP (nu) & $11.0(8.6-14.2)$ & $9.3(7.9-14.1)$ & 0.341 \\
\hline $\mathrm{nLFP}(\mathrm{nu})$ & $27.4(24.5-27.8)$ & $27.9(26.9-28.5)$ & 0.361 \\
\hline nHFP (nu) & $62.0(60.0-64.0)$ & $62.9(59.4-63.6)$ & 0.890 \\
\hline $\mathrm{nHFP} N_{\mathrm{T}}(\mathrm{nu} / \mathrm{ml})$ & $0.11(0.10-0.13)$ & $0.15(0.12-0.18)$ & 0.011 \\
\hline LHR & $0.45(0.43-0.47)$ & $0.45(0.44-0.48)$ & 0.937 \\
\hline $\mathrm{LHR}^{*} \mathrm{~V}_{\mathrm{T}}(1 / \mathrm{ml})$ & $228(209-282)$ & $186(149-238)$ & 0.010 \\
\hline \multicolumn{4}{|c|}{$\begin{array}{l}\text { Data are presented as medians (25\% - 75\% interquartile range). APACHE II: Acute Physiology and Chronic Health Evaluation II; ASA: American Society of } \\
\text { Anesthesiologists; VATS: Video-Assisted Thoracic Surgery; I/O: intake/output; RASS: Richmond Agitation-Sedation Scale; FIO2: fraction of inspired oxygen; PEEP: } \\
\text { positive end-expiratory pressure; RR: respiratory rate; Pinsp: inspiratory pressure; Tinsp: inspiration time; VT: tidal volume; MV: minute ventilation; Cdyn: dynamic } \\
\text { compliance; PaO2: partial pressure of arterial oxygen; PaCO2: partial pressure of arterial carbon dioxide; HCO3: bicarbonate; AaDO2: alveolo-arterial oxygen } \\
\text { difference; ALI score: acute lung injury score; RASS: Richmond Agitation-Sedation Scale; mRRI: mean RR interval; SDRR: standard deviation of RR intervals; CVRR: } \\
\text { coefficient of variation of RR intervals; RMSSD: root mean squared successive difference; TP: total power; VLFP: very low-frequency power; LFP: low-frequency } \\
\text { power; HFP: high-frequency power; nVLFP: normalized VLFP; nLFP: normalized LFP; nHFP: normalized HFP; body weight; LHR: } 4 \text { low-/high- frequency power ratio; } \\
\text { ml: milliliter; bpm: beats per minute; ms: milliseconds; nu: normalized unit; NA: not assessed. The "*" in "LHR*V" denotes multiplication }\end{array}$} \\
\hline
\end{tabular}

(95\% CI $=0.685-1.000 ; p=0.021)$ and 0.888 (95\% CI $=0$. $741-1.000 ; p=0.010)$, respectively. Among all variables assessed in this study, HFP was the best predictor in predicting mortality in ARDS patients on admission to the SICU.

Linear regression analysis was used to assess the association between ICU stay days (dependent variable) and HRV measures in ARDS patients. It was found that the TP $(p=0.681), \operatorname{LFP}(p=0.740), \operatorname{HFP}(p=0.686)$ and RASS $(p=0.108)$ were not significantly associated with the days of ICU stay of ARDS patients in the SICU (Table 5).

\section{Discussions}

Spectral HRV analysis allows us to differentiate between branches of the autonomic nervous system [12] and to assess the autonomic modulation of critically ill patients [16-22]. This study compared the clinical characteristics and HRV measures between non-ARDS and ARDS patients, and between ARDS patients who survived and did not survive. It was found that the HFP was significantly lower $(p=0.043)$ while the $n H F P / V_{\mathrm{T}}$ was significantly higher $(p=0.011)$ in the ARDS group compared with those in the non-ARDS group, and that the nonsurvived ARDS patients had higher TP, LFP, HFP, and $\mathrm{HFP} / \mathrm{V}_{\mathrm{T}}$ than the survived ARDS patients had. After adjustment for RASS, age and gender, firth logistic regression analysis identified HFP and TP as the independent predictors of mortality in ARDS patients on admission to the SICU. The HFP was found to be the best predictor of mortality in ARDS patients.

Many studies have proposed that clinical laboratory data and HRV measures can be used to predict the prognosis of certain diseases. For instance, Luhr et al. [30] showed that age and acute physiologic score were associated with mortality in the ARDS patients. Phillips et al. [31] had shown that the lung injury score of nonsurvivors was significantly higher than that of survivors in patients with ARDS. Swaroopa et al. [32] had shown that the APACHE II score was significantly higher in non-survivors as compared to survivors in patients with ARDS. In this study it was found that the APACHE II, ALIS, $\mathrm{PaO}_{2} / \mathrm{FIO}_{2}$ and $\mathrm{AaDO}_{2}$ were not significantly different between the survived and non-survived ARDS patients; instead, the HFP and TP were found to be the independent predictors of mortality in ARDS patients on admission to the SICU $(p<0.05)$. This result suggested that the non-invasive HRV indices such as HFP and TP were more sensitive than the conventional scores or indices such as APACHE II, ALIS, $\mathrm{PaO}_{2} / \mathrm{FIO}_{2}$ and $\mathrm{AaDO}_{2}$ in predicting the outcome of surgical patients with ARDS. Because of its non-invasiveness and close relation with the autonomic control of heart rate, HRV is often used in the monitoring and prognosis of critically ill 
Table 2 Comparison between survivors and non-survivors in patients with ARDS

\begin{tabular}{|c|c|c|c|}
\hline & $\begin{array}{l}\text { Survivors } \\
(n=16)\end{array}$ & $\begin{array}{l}\text { Non-survivors } \\
(n=5)\end{array}$ & $p$ value \\
\hline \multicolumn{4}{|l|}{ Clinical data } \\
\hline Age (year) & $59.5(41.8-70.0)$ & $71.0(59.5-77.5)$ & 0.136 \\
\hline Body height $(\mathrm{cm})$ & $167(163-170)$ & $166(154-170)$ & 0.835 \\
\hline Body weight (kg) & $64(59-71)$ & $62(57-80)$ & 0.773 \\
\hline ALI score & $13(10-14)$ & $13(12-15)$ & 0.557 \\
\hline APACHE $\|$ & $14(10-19)$ & $18(14-29)$ & 0.185 \\
\hline \multicolumn{4}{|l|}{ Pre-operation } \\
\hline Hypertension (Yes/No) & $2 / 14$ & $2 / 3$ & 0.228 \\
\hline ASA & $2(2-3)$ & $2(2-3)$ & 0.768 \\
\hline VATS/open surgery & $8 / 2$ & $4 / 1$ & 0.660 \\
\hline Surgery time (minute) & $210(280-457)$ & $320(220-345)$ & 1.000 \\
\hline Blood transfusion (Yes/No) & $5 / 5$ & $1 / 0$ & 0.719 \\
\hline Airway management & $7 / 3$ & $3 / 2$ & 0.768 \\
\hline \multicolumn{4}{|c|}{ (double-lumen tube/bronchus blocker) } \\
\hline Anesthesia (volatile/intravenous) & $10 / 0$ & $5 / 0$ & 1.000 \\
\hline Intraoperative I/O & $780(1350-1800)$ & $1300(600-1600)$ & 0.679 \\
\hline ICU stay days & $21(11-44)$ & $25(20-43)$ & 0.535 \\
\hline RASS & $-1(-1-0)$ & $-2(-2--1)$ & 0.040 \\
\hline Ventilator free hours & $48(24-68)$ & $0(0-10)$ & 0.177 \\
\hline Re-thoracotomy (Yes/No) & $0 / 16$ & $0 / 5$ & 1.000 \\
\hline Re-intubation rate (Yes/No) & $5 / 16$ & $2 / 0$ & 0.780 \\
\hline SOFA score & $8(7-10)$ & $7(7-8)$ & 0.313 \\
\hline WBC & $13.3(7.7-13.4)$ & $12.9(11.1-14.0)$ & 0.905 \\
\hline CRP & $21.5(10.9-22.6)$ & $12.4(11-19.7)$ & 0.495 \\
\hline \multicolumn{4}{|l|}{ Medications } \\
\hline Midazolam (Yes/No) & $15 / 1$ & $5 / 0$ & 1.000 \\
\hline Fentanyl (Yes/No) & $16 / 0$ & $5 / 0$ & 1.000 \\
\hline Norepinephrine (Yes/No) & $6 / 10$ & $2 / 3$ & 1.000 \\
\hline Dopamine (Yes/No) & $2 / 13$ & $1 / 4$ & 0.842 \\
\hline \multicolumn{4}{|l|}{ Ventilator settings } \\
\hline $\mathrm{FlO}_{2}$ & $0.70(0.56-0.94)$ & $0.65(0.60-0.93)$ & 0.901 \\
\hline PEEP $\left(\mathrm{cmH}_{2} \mathrm{O}\right)$ & $10.0(8.5-12.0)$ & $10.2(9.7-13.5)$ & 0.552 \\
\hline $\mathrm{RR}(\mathrm{bpm})$ & $16.5(15.3-23.0)$ & $26.0(20.0-27.5)$ & 0.156 \\
\hline$P_{\text {insp }}\left(\mathrm{cmH}_{2} \mathrm{O}\right)$ & $18.0(15.3-20.0)$ & $22.0(20.0-22.5)$ & 0.039 \\
\hline $\mathrm{T}_{\text {insp }}(\mathrm{sec})$ & $0.9(0.8-1.0)$ & $0.9(0.8-1.0)$ & 0.548 \\
\hline $\mathrm{V}_{\mathrm{T}}(\mathrm{ml})$ & $425(385-545)$ & $390(305-493)$ & 0.385 \\
\hline MV (I/min) & $8.0(6.6-10.5)$ & $10.2(6.9-12.9)$ & 0.363 \\
\hline Cdyn $\left(\mathrm{ml} / \mathrm{cmH}_{2} \mathrm{O}\right)$ & $21.6(18.5-32.0)$ & $19.0(13.9-23.4)$ & 0.231 \\
\hline \multicolumn{4}{|l|}{ Arterial gas analysis } \\
\hline $\mathrm{pH}$ & $7.42(7.38-7.45)$ & $7.47(7.42-7.49)$ & 0.074 \\
\hline $\mathrm{PaO}_{2}(\mathrm{mmHg})$ & $78(67-97)$ & $90(66-103)$ & 0.772 \\
\hline $\mathrm{PaCO}_{2}(\mathrm{mmHg})$ & $38(29-41)$ & $40(39-51)$ & 0.043 \\
\hline $\mathrm{HCO}^{-}(\mathrm{mmol} / \mathrm{l})$ & $24(19-27)$ & $30(28-33)$ & 0.003 \\
\hline
\end{tabular}


Table 2 Comparison between survivors and non-survivors in patients with ARDS (Continued)

\begin{tabular}{|c|c|c|c|}
\hline & $\begin{array}{l}\text { Survivors } \\
(n=16)\end{array}$ & $\begin{array}{l}\text { Non-survivors } \\
(n=5)\end{array}$ & $p$ value \\
\hline $\mathrm{PaO}_{2} / \mathrm{FIO}_{2}(\mathrm{mmHg})$ & $115(84-180)$ & $106(83-171)$ & 0.901 \\
\hline $\mathrm{AaDO}_{2}(\mathrm{mmHg})$ & $384(256-536)$ & $352(275-516)$ & 0.967 \\
\hline \multicolumn{4}{|c|}{ Time domain HRV measures } \\
\hline mRRI (ms) & $569(496-636)$ & $655(600-761)$ & 0.063 \\
\hline $\mathrm{SD}_{\mathrm{RR}}$ (ms) & $28(23-34)$ & $31(30-41)$ & 0.063 \\
\hline$C V_{R R}(\%)$ & $4.51(4.47-4.77)$ & $4.98(4.49-6.03)$ & 0.409 \\
\hline RMSSD (ms) & $27(23-35)$ & $34(31-44)$ & 0.052 \\
\hline \multicolumn{4}{|c|}{ Frequency domain HRV measures } \\
\hline $\mathrm{TP}\left(\mathrm{ms}^{2}\right)$ & $161(113-246)$ & $274(234-529)$ & 0.023 \\
\hline $\operatorname{VLFP}\left(\mathrm{ms}^{2}\right)$ & $13(9-55)$ & $22(20-70)$ & 0.231 \\
\hline $\operatorname{LFP}\left(m s^{2}\right)$ & $47(32-59)$ & $75(64-127)$ & 0.023 \\
\hline $\operatorname{HFP}\left(m s^{2}\right)$ & $101(71-133)$ & $175(148-335)$ & 0.012 \\
\hline $\operatorname{HFP} N_{T}\left(\mathrm{~ms}^{2} / \mathrm{ml}\right)$ & $0.23(0.18-0.32)$ & $0.64(0.35-0.82)$ & 0.007 \\
\hline nVLFP (nu) & $9.7(7.9-14.3)$ & $8.9(6.3-14.4)$ & 0.710 \\
\hline $\mathrm{nLFP}(\mathrm{nu})$ & $27.9(26.9-28.8)$ & $27.4(22.4-28.3)$ & 0.509 \\
\hline $\mathrm{nHFP}(\mathrm{nu})$ & $62.0(59.4-63.5)$ & $63.7(57.5-71.0)$ & 0.127 \\
\hline $\mathrm{nHFP} N_{\mathrm{T}}(\mathrm{nu} / \mathrm{ml})$ & $0.15(0.10-0.16)$ & $0.17(0.12-0.24)$ & 0.386 \\
\hline LHR & $0.45(0.44-0.48)$ & $0.43(0.33-0.50)$ & 0.127 \\
\hline $\mathrm{LHR}^{*} \mathrm{~V}_{\mathrm{T}}(1 / \mathrm{ml})$ & 189 (179-254) & 161 (95-238) & 0.302 \\
\hline
\end{tabular}

Data are presented as medians (25\% - 75\% interquartile). ALl: acute lung injury score; RASS: Richmond Agitation-Sedation Scale; RASS: Richmond AgitationSedation Scale; SOFA: Sequential Organ Failure Assessment; WBC: white blood cells; CRP: C-reactive protein. Other abbreviations are the same as those depicted in Table 1. The "*" in "LHR* $\mathrm{V}_{\mathrm{T}}$ " denotes multiplication

patients. For instance, Longin et al. [33] studied the differences in HRV variables during extracorporeal membrane oxygenation (ECMO) therapy between survivors $(n=6)$ and non-survivors $(n=7)$ and found that the survivors showed a tendentious, but not significant, decrease in HRV variables (ECMO-start vs. ECMO-stop), while the non-survivors had elevated HRV values. Winchell et al. [34] showed that both low TP and LHR were associated with increased mortality, while sympathetic predominance favored survival in the ICU setting. Chen et al. [35] found that a worse oxygenation status is associated with increased cardiac vagal and decreased cardiac sympathetic activities in patients with chronic obstructive pulmonary disease (COPD). For patients with sepsis in the emergency department, Chen et al. [36] also found that the SDNN,

Table 3 Correlation coefficient in the Pearson product moment correlation analyses of HRV parameters and RASS in patients with ARDS

\begin{tabular}{lllll}
\hline & LFP & HFP & HFP $N_{T}$ & RASS \\
\hline TP & $0.958^{*}$ & $0.955^{*}$ & $0.793^{*}$ & 0.181 \\
LFP & $0.870^{*}$ & $0.725^{*}$ & 0.235 \\
HFP & & $0.878^{*}$ & 0.019 \\
\hline${ }^{*} p<0.05$. HFP: high-frequency power; TP: total power; LFP: low-frequency \\
power; $V_{T}$ : tidal volume; RASS: Richmond Agitation-Sedation Scale
\end{tabular}

TP, VLFP, LFP, and LHR were all significantly lower while the nHFP was significantly higher in the non-survivors of sepsis. In another study, Chen et al. [20] further showed that the LFP, nLFP and LHR were significantly lower while the RMSSD, HFP, HFP/ $\mathrm{V}_{\mathrm{T}}$, $\mathrm{nHFP}$, and $\mathrm{nHFP} / \mathrm{V}_{\mathrm{T}}$ were significantly higher in the non-survivors of patients with outof-hospital cardiac arrest. These results suggested that HRV measures can be used in the monitoring and prognosis of critically ill patients, and that increased cardiac vagal and decreased cardiac sympathetic activities might be indicative of poor prognosis. In accordance with these studies, the present study also found that the ARDS patients had higher vagal modulation and smaller sympathetic modulation than the non-ARDS patients, and that the non-survived ARDS patients had higher vagal modulation than the survived ARDS patients. Further, Firth logistic regression analysis identified HFP and TP as the independent predictors of mortality in ARDS patients on admission to the SICU (Table 4). The HFP, an indicator of vagal modulation, appeared to be the best predictor of mortality in ARDS patients $(p=0.02)$. Thus the HFP might be useful in the monitoring and prediction of outcome in various critically ill patients, including ARDS, and be used in the prediction of mortality on their admission to the SICU. 
Table 4 Firth logistic regression analyses for predicting the mortality of patients with ARDS

\begin{tabular}{|c|c|c|c|c|c|c|}
\hline \multicolumn{3}{|c|}{ Univariate Model } & \multicolumn{2}{|c|}{$\begin{array}{l}\text { Multivariate model } 1 \\
\text { Adjusted for HFP, RASS, age and gender }\end{array}$} & \multicolumn{2}{|c|}{$\begin{array}{l}\text { Multivariate model } 2 \\
\text { Adjusted for TP, RASS, age and gender }\end{array}$} \\
\hline & OR $(95 \% \mathrm{Cl})$ & $p$ value & OR $(95 \% \mathrm{Cl})$ & $p$ value & OR $(95 \% \mathrm{Cl})$ & $p$ value \\
\hline HFP & $1.013(1.002,1.03)$ & 0.020 & $1.016(1.002,1.149)$ & 0.025 & & \\
\hline $\mathrm{TP}$ & $1.007(1.00,1.02)$ & 0.047 & & & $1.010(1.001,1.065)$ & 0.024 \\
\hline LFP & $1.021(0.998,1.05)$ & 0.080 & & & & \\
\hline
\end{tabular}

OR: odds ratio; $95 \% \mathrm{Cl}$ : 95\% profile-likelihood confidence intervals; HFP: high-frequency power; TP: total power; LFP: low-frequency power
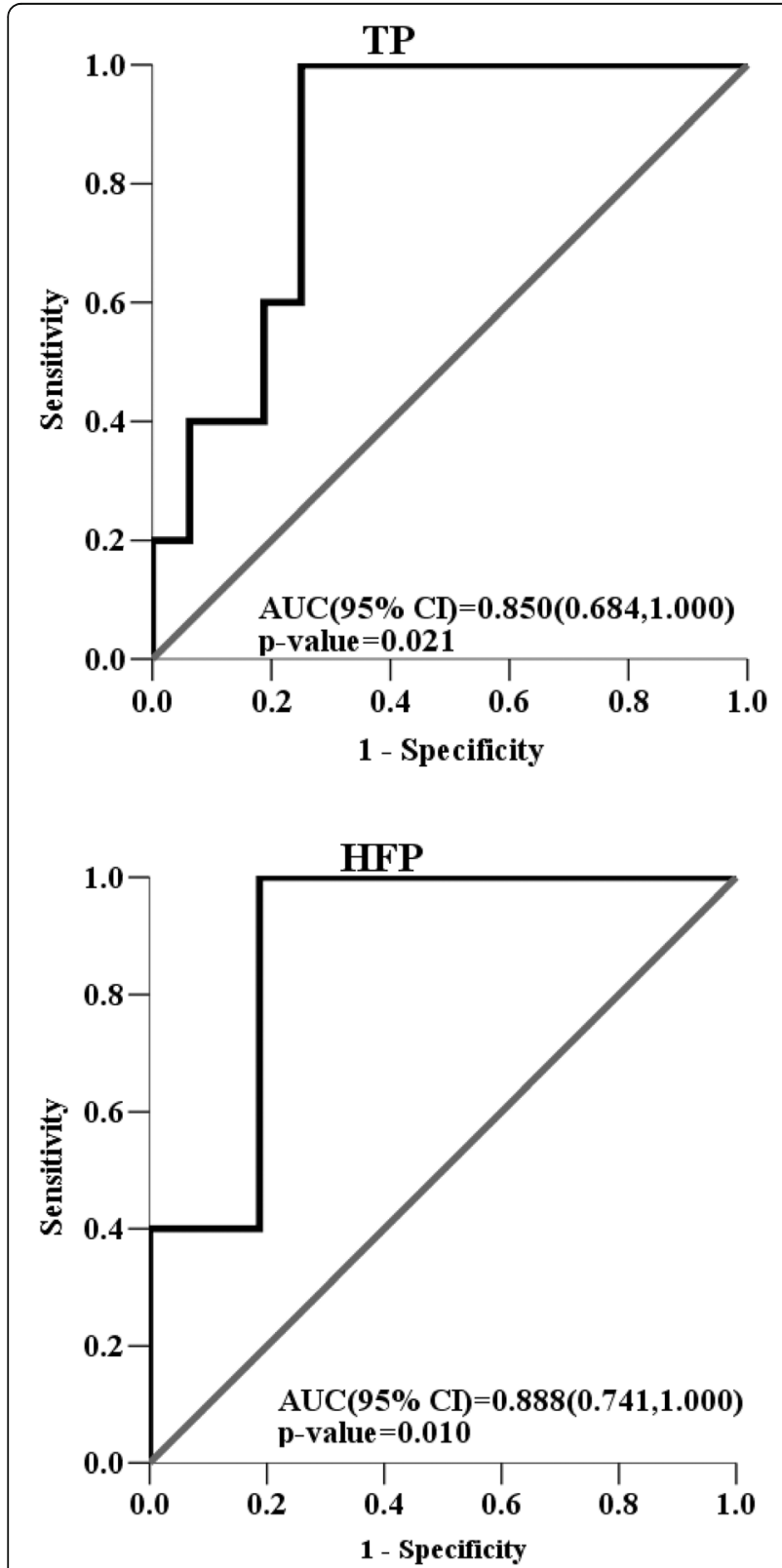

Fig. 1 The areas under the ROC curves (AUC) and 95\% confidence intervals $(\mathrm{Cl})$ of TP and HFP in predicting the mortality of ARDS patients on admission to the SICU were $0.850(95 \% \mathrm{Cl}=0.685-1.000$; $p=0.021)$, and $0.888(95 \% \mathrm{Cl}=0.741-1.000 ; p=0.010)$, respectively
The mechanism underlying the increase in vagal modulation in critically ill patients has not been well understood yet. It has been shown that direct electrical stimulation of the peripheral vagus nerve in vivo during lethal endotoxaemia in rats could inhibit tumor necrosis factor (TNF) synthesis in liver, attenuated peak serum TNF amounts, and prevented the development of shock [37]. Thus, the increased vagal modulation in ARDS patients might be one of the pathophysiological responses of the patient to counteract the cytokines synthesis, attenuate the amount of cytokines in the serum, and prevent the cytokines-induced systemic inflammation in ARDS. Since the non-survived ARDS patients had increased vagal modulation relative to the survived ARDS patients, the use of anticholinergic and sympathomimetic agents to correct their autonomic dysfunction might be considered in patients with ARDS after thoracic surgery. Further studies are warranted to investigate the underlying mechanism of increased vagal modulation in critically ill patients, including ARDS.

The HRV parameters in ARDS patients can be influenced by many interventions performed in the ICU, such as sedation, catecholamine therapy, volume management, ventilator settings, etc. Previous study has indicated that the increase in $V_{T}$ can increase the HFP component of HRV [26]. To minimize the effect of $V_{T}$ on the indicator of vagal modulation, a new indicator $\mathrm{nHFP} / \mathrm{V}_{\mathrm{T}}$ was used to represent the $\mathrm{V}_{\mathrm{T}}$-corrected indicator of vagal modulation. It was found that the ARDS patients still had higher vagal modulation than the nonARDS patients. Some studies had reported that

Table 5 Linear regression analyses for predicting the ICU stay days in patients with ARDS

\begin{tabular}{llll}
\hline & \multicolumn{2}{l}{ Univariate analysis } & \\
\cline { 2 - 3 } & \multicolumn{2}{l}{ Unstandardized coefficients } & \\
\cline { 2 - 3 } & $\mathrm{B}$ & Standard Error & \\
\hline TP & 0.005 & 0.011 & 0.681 \\
LFP & -0.008 & 0.024 & 0.740 \\
HFP & -0.005 & 0.012 & 0.686 \\
RASS & -0.615 & 0.361 & 0.108 \\
\hline
\end{tabular}

The ICU stay days were analyzed in In-transformation manner due to nonnormality property. HFP: high-frequency power; TP: total power; LFP: low-frequency power 
midazolam and inotropes might change the autonomic nervous activities of the patients [38, 39]. Though the midazolam and norepinephrine were used more frequently in the ARDS patients than the non-ARDS patients, the use of midazolam and norepinephrine were not significantly different between survivors and nonsurvivors of ARDS patients. Thus, the significantly increase in vagal modulation in the non-survivors of ARDS should not be caused by the use of midazolam and norepinephrine. In ARDS patients, PEEP has been widely used to improve arterial oxygenation; however, the increase in PEEP can reduce the baroreflex sensitivity, and can alter the autonomic nervous function in these patients [40]. The present study found that ARDS patients required higher PEEP during mechanical ventilation than the non-ARDS patients. Since the level of PEEP was not significantly different between the survivors and non-survivors of ARDS patients, the significantly increased vagal modulation in the non-survivors of ARDS patients should not be caused by the use of higher PEEP in those patients.

The major limitation of this study was the small number of ARDS patients. Since the incidence of ARDS is not very high in the post-operative patients with lung or esophageal cancer, it was not easy to collect a large number of cases for statistical analysis in a study period of 2 years.

\section{Conclusions}

The vagal modulation of thoracic surgical patients with ARDS was enhanced compared with non-ARDS patients. Non-survived ARDS patients had higher vagal activity than survived ARDS patients. The vagal modulationrelated parameter such as HFP and TP might be used as predictors to identify ARDS patients with high risk of mortality on admission to the SICU, especially the HFP. Increased vagal modulation might be an indicator for poor prognosis in critically ill patients following thoracic surgery, and anticholinergic and sympathomimetic agents might be tried to correct the autonomic dysfunction of ARDS patients.

\section{Abbreviations}

$\mathrm{AaDO}_{2}$ : Alveolar-arterial oxygen difference; ALIS: Acute lung injury score; APACHE: Acute Physiology and Chronic Health Evaluation; ARDS: Acute respiratory distress syndrome; ASA: American Society of Anesthesiologists; Cdyn: Dynamic compliance; COPD: Chronic obstructive pulmonary disease; $\mathrm{CV}_{\mathrm{RR}}$ : Coefficient of variation of RRI; ECG: Electrocardiographic;

ECMO: Extracorporeal membrane oxygenation; EPV - 10: 10 events per variable; $\mathrm{FIO}_{2}$ : Fraction of inspired oxygen; $\mathrm{HCO}_{3}^{-}$: Bicarbonate; HFP: Highfrequency power; HRV: Heart rate variability; I/O: Intake/output; ICU: Intensive care unit; LF: Low-frequency; LFP: Low-frequency power; LHR: Low-/highfrequency power ratio; mRRI: Mean RR interval; MV: Minute ventilation; nHFP: Normalized HFP; nLFP: Normalized LFP; nVLFP: Normalized VLFP; $\mathrm{PaCO}_{2}$ : Arterial partial pressure of carbon dioxide; $\mathrm{PaO}_{2}$ : Arterial partial pressure of oxygen; PEEP: Positive end-expiratory pressure; $P_{\text {insp }}$ : Inspiratory pressure; PSD: Power spectral density; RASS: Richmond Agitation-Sedation Scale; RMSSD: Root mean squared successive difference of RRI; ROC: Receiver operating characteristic; RR: Respiratory rate; RRI: RR intervals; SDNN: Standard deviation of normal-to-normal QRS intervals; SDRR: Standard deviation of RRI; SICU: Surgical intensive care unit; $T_{\text {insp: }}$ Inspiration time; TNF: Tumor necrosis factor; TP: Total power; VATS: Video-assisted thoracic surgery; VLFP: Very lowfrequency power; $V_{T}$ : Tidal volume

\section{Acknowledgements}

Not applicable.

\section{Funding}

This study was supported by a grant VGHUST99-P1-09 from the Veterans General Hospitals and University System of Taiwan Joint Research Program, Taiwan, and a grant 96VN-010 from the Taipei Veterans General Hospital-National Taiwan University Hospital Joint Research Program, Taipei, Taiwan. The funding bodies did not participate in the design of the study and collection, analysis, and interpretation of data and in writing the manuscript.

\section{Availability of data and materials}

The datasets used and/or analyzed during the current study available from the corresponding author on request.

\section{Authors' contributions}

ICC recruited the patients, collected the data, performed preliminary data analysis and drafted the manuscript. CTK performed detailed statistical analysis and prepared the fig. JK, CHL, JZT and WJK participated in the discussion and improved the manuscript. CDK made substantial contributions to the original idea and design, analyses and interpretation of data as well as revising the manuscript. CDK is the corresponding author and is responsible for the finalization of the manuscript. All authors have read and approved the final manuscript.

\section{Ethics approval and consent to participate}

The study protocol has been approved by the Institutional Review Boards of National Taiwan University Hospital (NTUH200808065R) and Taipei Veterans General Hospital (VGHIRB97-01-02A), and written informed consent was obtained from the next of kin of the patients before their enrollment in the study.

\section{Consent for publication}

All included patients or their family members signed the informed consent form to report individual patient data. All authors have confirmed the manuscript and approved the publication of the manuscript.

\section{Competing interests}

The authors declare that they have no competing interest.

\section{Publisher's Note}

Springer Nature remains neutral with regard to jurisdictional claims in published maps and institutional affiliations.

\section{Author details}

'Intensive Care Units, National Taiwan University Hospital, Taipei, Taiwan. ${ }^{2}$ Internal Medicine Research Center, Changhua Christian Hospital, Changhua, Taiwan. ${ }^{3}$ Division of Chest Medicine, Department of Internal Medicine, Changhua Christian Hospital, Changhua, Taiwan. ${ }^{4}$ Department of Respiratory Care, College of Health Sciences, Chang Jung Christian University, Tainan, Taiwan. ${ }^{5}$ School of Dentistry, College of Dental Medicine, Kaohsiung Medical University, Kaohsiung, Taiwan. ${ }^{6}$ Department of Electrical Engineering, National Central University, Jung-Li, Taoyuan, Taiwan. 'Laboratory of Biophysics, Department of Medical Research, Taipei Veterans General Hospital, Taipei, Taiwan.

Received: 27 June 2017 Accepted: 20 March 2018

Published online: 02 April 2018

\section{References}

1. Ashbaugh DG, Bigelow DB, Petty TL. et. al. Acute respiratory distress in adults. Lancet. 1967;2:319-23.

2. Definition Task Force ARDS, Ranieri VM, Rubenfeld GD, et al. Acute respiratory distress syndrome: the Berlin Definition. JAMA. 2012;307:2526-33. 
3. D'Journo XB, Michelet P, Avaro JP, et al. Respiratory complications after oesophagectomy for cancer. Rev Mal Respir. 2008;25:683-94.

4. Kim JB, Lee SW, Park SI, et al. Risk factor analysis for postoperative acute respiratory distress syndrome and early mortality after pneumonectomy: the predictive value of preoperative lung perfusion distribution. J Thorac Cardiovasc Surg. 2010;140:26-31.

5. Kometani T, Okamoto T, Yoshida S, et al. Acute respiratory distress syndrome after pulmonary resection. Gen Thorac Cardiovasc Surg. 2013;61:504-12.

6. Dulu A, Pastores SM, Park B, et al. Prevalence and mortality of acute lung injury and ARDS after lung resection. Chest. 2006;130:73-8.

7. Ware LB, Matthay MA. The acute respiratory distress syndrome. N Engl J Med. 2000;342:1334-49.

8. Tandon S, Batchelor A, Bullock R, et al. Peri-operative risk factors for acute lung injury after elective oesophagectomy. Br J Anaesth. 2001;86:633-8.

9. Navarrete-Navarro P, Ruiz-Bailén M, Rivera-Fernández R, et al. Acute respiratory distress syndrome in trauma patients: ICU mortality and prediction factors. Intens Care Med. 2000;26:1624-9.

10. Luecke $T$, Muench $E$, Roth $H$, Friess $U$, et al. Predictors of mortality in ARDS patients referred to a tertiary care centre: a pilot study. Eur J Anaesthesiol. 2006;23:403-10.

11. Bauman ZM, Gassner MY, Coughlin MA, et al. Lung injury prediction score is useful in predicting acute respiratory distress syndrome and mortality in surgical critical care patients. Crit Care Res Pract. 2015;2015: 157408. https://doi.org/10.1155/2015/157408.

12. Task Force of the European Society of Cardiology and the North American Society of Pacing and Electrophysiology. Heart rate variability: standards of measurement, physiological interpretation and clinical use. Eur Heart J. 1996;17(3):354-81. Circulation. 1996;93:1043-65.

13. Huikuri HV, Linnaluoto MK, Seppanen T, et al. Circadian rhythm of heart rate variability in survivors of cardiac arrest. Am J Cardiol. 1992;70:610-5.

14. Liu PY, Tsai WC, Lin $L$, et al. Time domain heart rate variability as a predictor of long-term prognosis after acute myocardial infarction. J Formos Med Assoc. 2003;102:474-9.

15. Erdogan $A$, Coch $M$, Bilgin $M$, et al. Prognostic value of heart rate variability after acute myocardial infarction in the era of immediate reperfusion. Herzschrittmacherther Elektrophysiol. 2008;19:161-8.

16. Tibby SM, Frndova H, Durward A, Cox PN. Novel method to quantify loss of heart rate variability in pediatric multiple organ failure. Crit Care Med. 2003; 31:2059-67.

17. Annane D, Trabold F, Sharshar T, et al. Inappropriate sympathetic activation at onset of septic shock: a spectral analysis approach. Am J Respir Crit Care Med. 1999;160:458-65.

18. Pontet J, Contreras P, Curbelo A, et al. Heart rate variability as early marker of multiple organ dysfunction syndrome in septic patients. J Crit Care. 2003; 18:156-63.

19. Yien HW, Hseu SS, Lee LC, et al. Spectral analysis of systemic arterial pressure and heart rate signals as a prognostic tool for the prediction of patient outcome in the intensive care unit. Crit Care Med. 1997;25:258-66.

20. Chen WL, Tsai TH, Huang CC, et al. Heart rate variability predicts short-term outcome for successfully resuscitated patients with out-of-hospital cardiac arrest. Resuscitation. 2009;80:1114-8.

21. Chen WL, Shen YS, Huang CC, et al. Postresuscitation autonomic nervous modulation after cardiac arrest resembles that of severe sepsis. Am J Emerg Med. 2012;30:143-50.

22. Chen WL, Kuo CD. Characteristics of heart rate variability can predic impending septic shock in emergency department patients with sepsis. Acad Emerg Med. 2007;14:392-7.

23. Yadav $H$, Thompson BT, Gajic O. Fifty years of research in ARDS: Is acute respiratory distress syndrome a preventable disease? Am J Respir Crit Care Med. 2017;195:725-36.

24. Murray JF, Matthay MA, Luce JM, et al. An expanded definition of the adult respiratory distress syndrome. Am Rev Respir Dis. 1988;138:720-3.

25. Knaus WA, Draper EA, Wagner DP, Zimmerman JE. APACHE II: a severity of disease classification system. Crit Care Med. 1985;13:818-29.

26. McClellan JH, Schafer RW, Yoder MA. Signal Processing First. New Jersey: Prentice Hall; 2003.

27. Pöyhönen M, Syväoja S, Hartikainen J, et al. The effect of carbon dioxide, respiratory rate and tidal volume on human heart rate variability. Acta Anaesthesiol Scand. 2004;48:93-101.
28. Peduzzi P, Concato J, Kemper $E$, et al. A simulation study of the number of events per variable in logistic regression analysis. J Clin Epidem. 1996;49:1373-9.

29. Hosmer DW, Lemeshow S. Applied Logistic Regression. 2nd ed. Hoboken, NJ: Wiley Online Library; 2000.

30. Luhr OR, Karlsson M, Thorsteinsson A, Rylander C, Frostell CG. The impact of respiratory variables on mortality in non-ARDS and ARDS patients requiring mechanical ventilation. Intens Care Med. 2000;26:508-17.

31. Phillips $C R$, Chesnutt MS, Smith SM. Extravascular lung water in sepsisassociated acute respiratory distress syndrome: Indexing with predicted body weight improves correlation with severity of illness and survival. Crit Care Med. 2008;36:69-73

32. Swaroopa D, Bhaskar K, Mahathi T, et al. Association of serum interleukin-6, interleukin-8, and Acute Physiology and Chronic Health Evaluation II score with clinical outcome in patients with acute respiratory distress syndrome. Indian J Crit Care Med. 2016;20:518-25.

33. Longin E, Schaible T, Demirakca S, et al. Heart rate variability during extracorporeal membrane oxygenation and recovery in severe neonatal disease. Early Hum Dev. 2006;82:135-42.

34. Winchell RJ, Hoyt DB. Spectral analysis of heart rate variability in the ICU: a measure of autonomic function. J Surg Res. 1996;63:11-6.

35. Chen WL, Chen GY, Kuo CD. Hypoxemia and autonomic nervous dysfunction in patients with chronic obstructive pulmonary disease. Respir Med. 2006:100:1547-53.

36. Chen $\mathrm{WL}$, Chen $\mathrm{JH}$, Huang CC, et al. Heart rate variability measures as predictors of in-hospital mortality in ED patients with sepsis. Am J Emerg Med. 2008;26:395-401.

37. Borovikova LV, Ivanova S, Zhang M, et al. Vagus nerve stimulation attenuates the systemic inflammatory response to endotoxin. Nature. 2000; 405:458-62.

38. Win NN, Fukayama $H$, Kohase $H$, et al. The different effects of intravenous propofol and midazolam sedation on hemodynamic and heart rate variability. Anesth Analg. 2005;101:97-102.

39. Kasaoka S, Nakahara T, Kawamura Y, et al. Real-time monitoring of heart rate variability in critically ill patients. J Crit Care. 2010;25:313-6.

40. Van de Louw A, Medigue C, Papelier Y, et al. Positive end-expiratory pressure may alter breathing cardiovascular variability and baroreflex gain in mechanically ventilated patients. Respir Res. 2010;11:38.

\section{Submit your next manuscript to BioMed Central and we will help you at every step:}

- We accept pre-submission inquiries

- Our selector tool helps you to find the most relevant journal

- We provide round the clock customer support

- Convenient online submission

- Thorough peer review

- Inclusion in PubMed and all major indexing services

- Maximum visibility for your research

Submit your manuscript at www.biomedcentral.com/submit 